\title{
National Policies for Internationalization
}

Do They Work?

\author{
Robin Matross Helms and Laura E. Rumbley
}

In response to the demands and opportunities of an everglobalizing world, governments in a wide range of countries are introducing policies and programs to promote higher education internationalization. These initiatives are underpinned by a variety of academic, economic, political, social, and cultural motivations; sometimes higher education internationalization is an explicit goal, while in other cases, the focus is more specifically on a discrete activity, or on broader national policy goals.

A recent study by the American Council on Education (ACE) and the Boston College Center for International Higher Education (CIHE) took a close look at the content of such policies - an overview, including a wide assortment of specific examples, is the basis for our recent report, Internationalizing Higher Education Worldwide: National Policies and Programs. Our analysis revealed five main categories of policies in place around the world, based on their primary focus:

Type 1: Student mobility. Policies designed to encourage and facilitate student mobility stand out as the most common focal point for policymaking related to internationalization of higher education. A broad array of nationally funded student mobility scholarship programs - from Saudi Arabia to Chile, Kazakhstan to Brazil, among many others - are the prime manifestations of this policy focus.

Type 2: Scholar mobility and research collaboration. Policy activity in this area is being undertaken by many countries around the world, as well as by key regions - notably Europe, where the European Union is investing heavily in this area under the Horizon 2020 initiative, and specifically through such mechanisms as the Marie Skłodowska-Curie actions. Common types of initiatives in this category include support for visiting scholars, programs, and grants to send faculty abroad, policies to repatriate faculty living in other countries, and project-based research grants.

Type 3: Cross-border education. Whether involving branch campuses and other kinds of physical "outposts," or virtual (or hybrid) forms — such as Moocs - national policy and program activity in this realm include initiatives to foster partnerships for capacity building, create educational "hubs," 
encourage domestic institutions to establish campuses and programs abroad, and more effectively regulate cross-border activity in practice.

Type 4: Internationalization at home ( $\mathrm{IaH})$. $\mathrm{IaH}$ is a nascent but rapidly emerging critical focal point for internationalization. Few policy documents currently address it overtly. The European Commission's 2013 strategy for internationalization, "European Higher Education in the World", is a notable exception. But this is surely an important space to watch for future policy developments.

Type 5: "Comprehensive internationalization" policies. We see a small number of initiatives that present a rather sweeping set of rationales, action lines, focus areas, and/or geographic orientations, rather than being singularly focused on specific action lines. Again, the European Commission's policy vision for internationalization stands out, but so does Canada's 2014 "International Education Strategy" and Malaysia's 2011 "Internationalization Policy for Higher Education Malaysia," among others.

\section{Gauging Effectiveness}

With national-level internationalization policies and programs proliferating in a variety of contexts and configurations, the question of effectiveness comes front and center. Do these policies positively impact the direction and progress of internationalization in their respective higher education systems? In the longer term, do they succeed in furthering the academic, economic, political, social, and/or cultural goals they set out to achieve?

As is often the case when it comes to education-related issues, determining the effectiveness of internationalization policies is challenging. Often, efforts to do so focus on easily measured, clearly quantified outputs. Did country A's policy achieve its goal of recruiting X number of new international students to the country's universities in the specified timeline? In addition to participant numbers, financial analyses - another easily quantified measure, and one that often appeals to policy-makers - may come into play as an evaluation tool.

When it comes to the more nebulous, longer-term outcomes, and impact of such policies, studies by the British Council/DAAD and the HEFCE (the Higher Education Funding Council for England), the European Commission, and the International Association of Universities have made some inroads in delineating impacts of different policies, using various methodologies. Overall, though, specific data and clear answers about issues of impact are fairly scarce. In part, this is due to the newness of many of the internationalization policies now in place around the world-it is simply too soon to tell what their ultimate 
impact will be. In many other cases, evaluation of impact simply appears not be built into policy implementation structures.

Having examined a large number of such policies and the available data on effectiveness, however, it is clear that there are a number of key factorsboth inherent to the policies themselves, as well as external factors impacting implementation - that affect policy effectiveness (positively or negatively).

Funding is of primary importance. Not surprisingly, policy effectiveness may be directly affected by issues such as the level at which policies are funded, the ways in which funding is distributed, and the degree to which funding is sustained over time.

How policies are implemented, and by whom, is also crucial. It is common knowledge that "one size fits all" is not a useful way to think about internationalization policy or practice. So, national policies may be implemented in a wide variety of ways - for example, involving many actors or just a few. The ways that policies are implemented can have a major effect on issues such as efficiency, and raise important questions about the capacity of policy implementers to advance their agendas and manage their work well.

Looking beyond individual policies themselves gives rise to the issue of policy interplay and alignment. For most countries, the national policy environment is complex and interlocking. Initiatives undertaken in one area can have a direct influence on efforts being undertaken in other policy spheres. Classic examples in relation to internationalization include the intersection between national objectives to attract international students and scholars, and visa and immigration policies that control access to the country. If policies are developed and implemented in isolation from one another, or directly at crosspurposes, policy effectiveness will suffer.

Finally, the level of convergence between policy objectives and institutional priorities impacts effectiveness of national-level initiatives. Internationalization of higher education is a phenomenon most directly experienced by higher education institutions themselves. For this reason, national policies for internationalization must be grounded in an understanding of institutional realities. National policies that fail to take into account institutional priorities, and vice versa, present major challenges for achieving successful outcomes.

Will individual countries' internationalization policies ultimately achieve their short-and long-term goals? Only time will tell. But, perhaps the more interesting question is what the overall impact of such policies will be on 
higher education worldwide. The growing number of countries that are committing - in very concrete, formal, and resource-intensive ways- to internationalizing their higher education systems suggests that the time is right to collectively take our efforts to the next level, and turn our attention to the "internationalization of internationalization." The impact of country-level policies will be maximized when we find the synergies among them-i.e., when our policies are mutually supportive and reinforcing.

This is not necessarily an easy task - it requires broad awareness of policies in place, and dialogue at the national policymaking and institutional levels. As we note at the end of the ACE-CIHE report, "ensuring that higher education around the world benefits from the best of what comprehensive, sustained, values-driven internationalization has to offer will take a great deal of creativity, substantial resources, and sheer hard work."

\section{Acknowledgement}

This chapter was previously published in International Higher Education, No. 85, Spring 2016 (pp. 10-12). Reprinted here with permission. 